\title{
Multicomponent fortification of human breast milk for preterm infants following hospital discharge (Review)
}

\author{
Henderson G, Fahey T, McGuire W
}

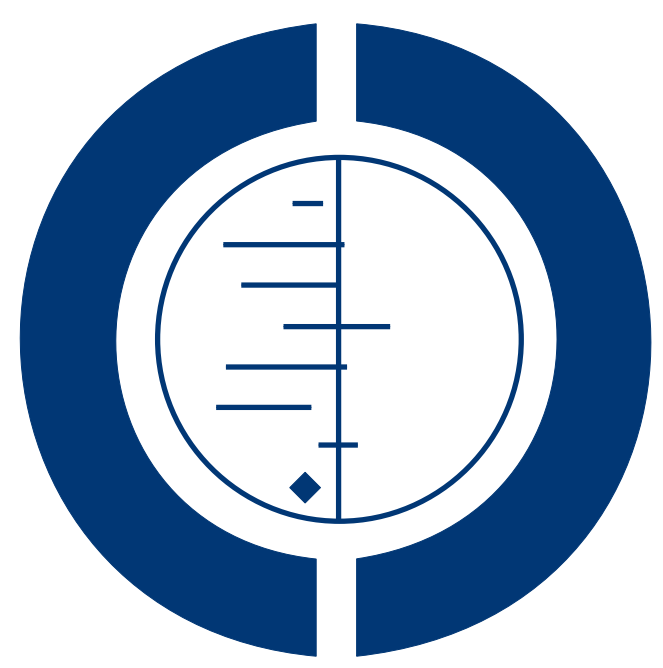

\section{THE COCHRANE COLLABORATION $^{\circledR}$}

This is a reprint of a Cochrane review, prepared and maintained by The Cochrane Collaboration and published in The Cochrane Library 2009, Issue 3

http://www.thecochranelibrary.com

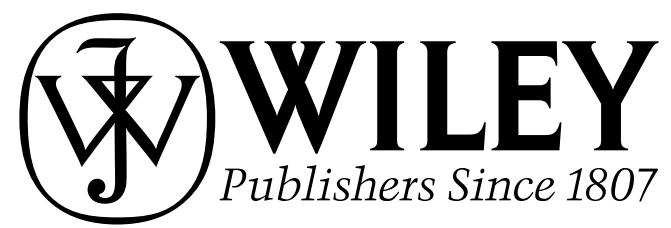

Multicomponent fortification of human breast milk for preterm infants following hospital discharge (Review)

Copyright (C) 2009 The Cochrane Collaboration. Published by John Wiley \& Sons, Ltd. 
TABLE OF CONTENTS

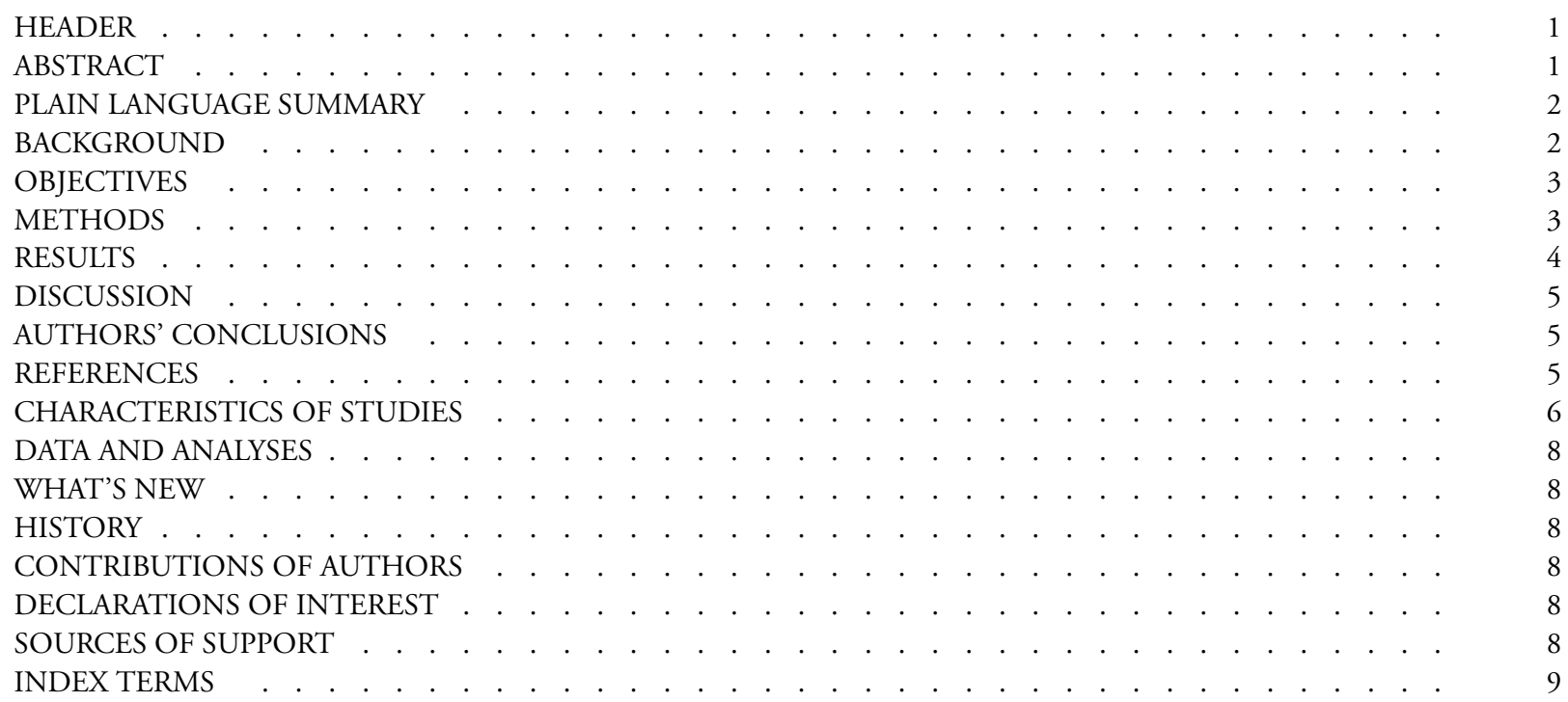

Multicomponent fortification of human breast milk for preterm infants following hospital discharge (Review)

Copyright @ 2009 The Cochrane Collaboration. Published by John Wiley \& Sons, Ltd. 


\title{
[Intervention Review] \\ Multicomponent fortification of human breast milk for preterm infants following hospital discharge
}

\author{
Ginny Henderson ${ }^{2}$, Tom Fahey ${ }^{3}$, William McGuire ${ }^{1}$ \\ ${ }^{1}$ Department of Paediatrics and Child Health, Australian National University Medical School, Canberra, Australia. ${ }^{2}$ School of Nursing \\ and Midwifery, Griffith University, South Brisbane, Australia. ${ }^{3}$ Department of Family Medicine and General Practice, Royal College \\ of Surgeons in Ireland Medical School, Dublin, Ireland \\ Contact address: William McGuire, Department of Paediatrics and Child Health, Australian National University Medical School, Can- \\ berra Hospital Campus, Canberra, ACT 2606, Australia. william.mcguire@act.gov.au. (Editorial group: Cochrane Neonatal Group.)
}

Cochrane Database of Systematic Reviews, Issue 3, 2009 (Status in this issue: Unchanged)

Copyright (C) 2009 The Cochrane Collaboration. Published by John Wiley \& Sons, Ltd.

DOI: 10.1002/14651858.CD004866.pub2

This version first published online: 17 October 2007 in Issue 4, 2007.

Last assessed as up-to-date: 29 May 2007. (Help document - Dates and Statuses explained)

This record should be cited as: Henderson G, Fahey T, McGuire W. Multicomponent fortification of human breast milk for preterm infants following hospital discharge. Cochrane Database of Systematic Reviews 2007, Issue 4. Art. No.: CD004866. DOI: 10.1002/14651858.CD004866.pub2.

\section{A B S T R A C T}

Background

Preterm infants are usually growth restricted at hospital discharge. Feeding preterm infants after hospital discharge with nutrientfortified breast milk (rather than unfortified breast milk) may facilitate more rapid catch-up growth and improve neurodevelopmental outcomes.

\section{Objectives}

To determine the effect of feeding with multicomponent fortified human breast milk versus unfortified breast milk on growth and development on preterm or low birth weight infants following hospital discharge.

\section{Search strategy}

The standard search strategy of the Cochrane Neonatal Review Group was used. This included searches of the Cochrane Central Register of Controlled Trials (CENTRAL, The Cochrane Library, Issue 2, 2007), MEDLINE (1966 - May 2007), EMBASE (1980 May 2007), CINAHL (1982 - May 2007), conference proceedings, and previous reviews.

\section{Selection criteria}

Randomised or quasi-randomised controlled trials that compared feeding preterm infants following hospital discharge with multicomponent fortified breast milk compared with unfortified human breast milk.

Data collection and analysis

The standard methods of the Cochrane Neonatal Review Group were used, with separate evaluation of trial quality and data extraction by two review authors.

Main results

No eligible trials were identified.

Authors' conclusions

Multicomponent fortification of human breast milk for preterm infants following hospital discharge (Review)

Copyright (C) 2009 The Cochrane Collaboration. Published by John Wiley \& Sons, Ltd. 
There are no data from randomised controlled trials to determine whether feeding preterm infants following hospital discharge with multicomponent-fortified breast milk compared with unfortified breast milk affects growth and development. Given the potential for nutrient fortification to affect growth and development, this intervention may merit further assessment. Since fortifying breast milk for infants fed directly from the breast is logistically difficult (and has the potential to interfere with breast-feeding), it would be important to determine if mothers would support a trial of this intervention. It may be that a trial should first focus on infants who are not able to consume ad libitum quantities of breast milk directly from the breast, who have poor growth or nutritional status, or who have ongoing additional metabolic requirements.

\section{PLAIN LANGUAGESUMMARY}

\section{Multicomponent fortification of human breast milk for preterm infants following hospital discharge}

Preterm infants are often much smaller than term infants by the time that they are discharged home from hospital. This review attempted to identify trials that evaluate whether feeding these infants with breast milk fortified with added nutrients rather than unfortified breast milk would increase growth rates and benefit development. No trials of this intervention were found. Whether undertaking such trials would be acceptable to mothers of preterm infants is not known.

\section{B A C K G R O U N D}

Most preterm infants accumulate significant energy, protein, mineral, and other nutrient deficits by the time of discharge from hospital (Embleton 2001). At this stage, many preterm infants are significantly growth-restricted, the risk of growth restriction increasing with decreasing gestational age and birth weight (Lucas 1984; Clark 2003). Following hospital discharge, demand fed preterm infants can consume greater volumes of milk than term infants in order to attain some "catch up" growth (Lucas 1992). Despite this, growth deficit persists throughout infancy and beyond (Morley 2000; Ford 2000). Poor postnatal growth in preterm infants, especially of the head, is associated with an increased risk of neurodevelopmental impairment in later childhood, as well as with poorer cognitive and educational outcomes (Cooke 2003; Hack 1991). Preterm infants who have accumulated deficits in calcium and phosphate by the time of hospital discharge are at increased risk of poor bone mineralisation, metabolic bone disease, and slower skeletal growth compared to infants born at term (Rigo 2000). There is also some concern that nutritional deficiency and growth restriction both in-utero and in the early postnatal period may have consequences for long-term cardiovascular health (Barker 2002).

Although human milk is the recommended nutritional source for newborn infants for at least the first six months of postnatal life (WHO 2001), unfortified human breast milk may not meet the nutritional needs of growing preterm infants (Tsang 1993). Feeding preterm infants prior to hospital discharge with expressed human breast milk fortified with energy, protein, and minerals is associated with short-term increases in weight gain, linear and head growth (Kuschel 2004a). However, there is not any evidence of long-term effects on growth or neurodevelopmental outcomes.
There is an opportunity for continued nutritional supplementation for preterm infants in the post-hospital discharge period of early infancy. Increased nutritional input during this period may be especially important for infants who have poor growth or nutritional status, or who have on-going additional metabolic requirements, for example, due to chronic lung disease (Cooke 2000; Griffin 2002). The available multicomponent breast milk fortifiers contain varying amounts of protein, carbohydrate, minerals, and vitamins (Simmer 2000). These liquid and powder formulations of multicomponent fortifiers must be mixed with expressed breast milk for delivery. Following hospital discharge, human milk-fed preterm infants usually obtain the majority of their milk directly from their mother's breast. Consequently, standard clinical practice has been to cease nutrient supplementation with multicomponent fortifiers during the period prior to hospital discharge when breast feeding is being established.

Multicomponent fortification may be more practical for infants who are not fed directly from the breast, but who are fed expressed breast milk. Multicomponent fortification may be especially important for infants who receive donated expressed breast milk, which contains lower levels of energy, protein and minerals than maternal expressed breast milk (Gross 1980). Although mothers who are feeding their infants directly from the breast may also express breast milk and give at least some fortified feeds via a bottle, cup, or feeding tube, this medicalisation of infant feeding might alter the maternal perception that breast milk is the preferred nutrition for her infant and interfere with the continuation of exclusive breast milk feeding.

Another putative disadvantage of multicomponent fortification of 
breast milk is that increasing the nutrient density and osmolarity of breast milk might interfere with gastric emptying and intestinal peristalsis, resulting in feed intolerance, vomiting or diarrhoea. Observational studies have provided conflicting evidence on these potential adverse effects (Ewer 1996; McClure 1996). The Cochrane review of multicomponent fortification of human milk for preterm infants prior to hospital discharge did not find any evidence of an increased incidence of clinically significant gastrointestinal adverse effects in infants who received fortified milk (Kuschel 2004a). There is also concern that excessive protein supplementation may cause metabolic stresses resulting in acidosis or elevated blood urea levels. However, the Cochrane review of multicomponent fortification of human milk for preterm infants prior to hospital discharge, and also the Cochrane review that specifically examined the effect of protein supplementation for preterm infants prior to hospital discharge, did not find evidence that blood urea rose to levels outside with normal reference ranges (Kuschel 2004a, Kuschel 2004b)

\section{O B J E C T IVES}

To determine the effect of feeding with multicomponent fortified human breast milk versus unfortified breast milk on growth and development in preterm infants following hospital discharge.

The following subgroup analyses were prespecified:

1. very low birth weight (less than 1.5 kilograms) or very preterm (less than 32 weeks') infants

2. infants who were small for gestational age (less than tenth percentile for the index population's distribution of weight) at hospital discharge

3. infants with chronic lung disease requiring home supplemental oxygen therapy

4. infants who receive donated expressed breast milk

\section{METHODS}

\section{Criteria for considering studies for this review}

\section{Types of studies}

Controlled trials using random or quasi-random patient allocation. Studies published only as abstracts were eligible for inclusion provided assessment of study quality was possible and other criteria for inclusion fulfilled.

\section{Types of participants}

Preterm infants (less than 37 weeks' gestation at birth) and low birth weight infants (less than 2.5 kilograms) receiving human breast milk following discharge from hospital.

\section{Types of interventions}

Multicomponent fortification: Supplementation of human breast milk with more than one nutrient (protein, fat, carbohydrate, or minerals [calcium and/or phosphate]), versus feeding with unsupplemented human milk. Supplementation with electrolytes, vitamins, or trace minerals in addition to only one of the above nutrients was not classified as multicomponent fortification for the purposes of this review. No restrictions to the pre-hospital discharge feeding regimes were prespecified. The intervention may have begun up to one week prior to planned discharge from hospital. Trials that randomly assigned infants to begin the study feed more than one week prior to hospital discharge (and then continued the intervention after hospital discharge) were not included in this review. Eligible studies should have planned to allocate the trial intervention for a sufficient period (at least two weeks) to allow measurable effects on growth. Infants in the groups within each study should have received similar care other than the type of formula milk. For example, there should not be any within-study differences in the prescription of target levels of volume of intake, or advice or support for demand feeding.

\section{Types of outcome measures}

\section{Primary:}

1. Long-term growth: Proportion of infants who remain below the tenth percentile for the index population's distribution of weight, height, or head circumference when assessed at $6-12$ months corrected age, or at 1218 months corrected age, and beyond.

2. Neurodevelopmental outcomes at greater than, or equal to, 12 months of age (corrected for preterm birth) measured using validated assessment tools such as Bayley Scales of Infant Development, and classifications of disability, including auditory and visual disability. Severe neurodevelopmental disability will be defined as any one or combination of the following: non-ambulant cerebral palsy, developmental delay (developmental quotient less than 70), auditory and visual impairment.

Secondary:

1. Growth during the trial period: Weight gain (grams per day, or grams per kilogram per day), linear growth (millimetres per week), head growth (millimetres per week), skinfold thickness growth (millimetres per week)

2. Cognitive and educational outcomes at aged more than five years old: Intelligence quotient and/or indices of educational achievement measured using a validated assessment tool (including school examination results) 
3. Measures of bone mineralisation at the end of the trial period: a. serum alkaline phosphatase level, b. bone mineral content assessed by dual energy $\mathrm{x}$ ray absorptiometry

4. Feed intolerance defined as vomiting or diarrhoea that results in the infant requiring treatment for dehydration (for example, oral rehydration solution, or hospital admission, or intravenous rehydration)

5. Duration of breast milk-feeding (time from start of trial until infant stops receiving any human breast milk)

6. Clinical or radiological evidence of rickets on long-term follow-up

7. Blood pressure on long-term follow-up

8. Body mass index on long-term follow-up

\section{Search methods for identification of studies}

The standard search strategy of the Cochrane Neonatal Review Group was used. This consisted of searches of the Cochrane Central Register of Controlled Trials (CENTRAL, The Cochrane Library, Issue 2, 2007), MEDLINE (1966- May 2007), and EMBASE (1980 - May 2007), and CINAHL (1982- May 2007). The electronic search used the following text words and MeSH terms: [Infant, Newborn OR Infant, Premature OR Infant, Low Birth Weight OR infan* OR neonat*] AND “Infant-Nutrition"/ all subheadings OR Milk, Human OR milk OR breast OR fortif* OR supplement ${ }^{*}$. The search outputs were limited with the relevant search filters for clinical trials. No language restriction was applied. References in previous reviews and studies were examined. Abstracts presented at the Society for Pediatric Research, European Society for Pediatric Research, the North American Society of Pediatric Gastroenterology and Nutrition, and the European Society of Paediatric Gastroenterology, Hepatology and Nutrition between 1990 and 2006/7 were searched. Trials reported only as abstracts were eligible if sufficient information was available from the report, or from contact with the authors, to fulfil the inclusion criteria. The UK National Research Register (http://www.nrr.nhs.uk), and Current Controlled Trials (http://www.controlled-trials.com) websites were searched for completed or ongoing trials.

\section{Data collection and analysis}

1. The title and abstract of all studies identified by the above search strategy were screened and the full articles for all potentially relevant trials obtained. The full text of any potentially eligible reports was re-assessed and those studies that did not meet all of the inclusion criteria were excluded. Any disagreements were discussed until consensus was achieved. Authors of studies published as abstracts were contacted for further information.
2. We planned to use the criteria and standard methods of the Cochrane Neonatal Review Group were used to assess the methodological quality of the trials in terms of allocation concealment, blinding of parents, carers, and assessors to the intervention, and completeness of assessment in all randomised individuals.

3. We planned to use a data collection form was used to extract relevant information. If data from the trial reports were insufficient, he trialists were contacted for further information.

4. We planned to present outcomes for categorical data were presented as relative risk, risk difference, and number needed to treat. For continuous data, the weighted mean difference (with respective $95 \%$ confidence intervals) was presented.

5. We planned to estimate the treatment effects of individual trials and heterogeneity between trial results was examined by inspecting the forest plots and quantifying the impact of heterogeneity in meta-analyses using a measure of the degree of inconsistency in the studies' results (I- squared statistic). If statistical heterogeneity was detected, the possible causes (for example, differences in study quality, participants, intervention regimens, or outcome assessments) were explored using post-hoc sub group analyses. A fixed effects model was planned for meta-analyses.

\section{R E S U L T S}

\section{Description of studies}

See: Characteristics of excluded studies; Characteristics of studies awaiting classification.

No eligible trials were identified. One trial, currently published in abstract form only, may be included in an update when further methodological details are available (O'Connor 2007). Another trial was excluded as the intervention group received only mineral fortification (Hall 1993).

\section{Risk of bias in included studies}

No eligible trials were identified.

\section{Effects of interventions}

No eligible trials were identified. 


\section{DISCUSSION}

No trials that assessed the effect of multicomponent nutrient fortification of breast milk for preterm infants following hospital discharge were identified. One trial that may be eligible for inclusion when sufficient methodological and other data are published was identified (O'Connor 2007). When these data are available, the trial will be evaluated for inclusion in a review update.

Multicomponent nutrient fortification of human breast milk has become an established intervention for increasing nutrient input and short-term growth rates for preterm infants while in hospital ( Kuschel 2004a). When infants are being readied for discharge, and ad libitum breast feeding established, nutrient fortification is generally stopped. Therefore, most breast milk-fed preterm infants do not receive nutrient supplements (apart from vitamins and iron) following hospital discharge. It is plausible that continuing to supply nutrient fortification after hospital discharge may increase nutrient intake and catch-up growth rates, and improve neurodevelopmental outcomes for breast milk-fed preterm infants. However, there are practical difficulties in adding powder or liquid fortifier to breast milk for infants fed directly from the breast, and concern that this may interfere with the establishment and continuation of breast feeding. Furthermore, evidence exists that preterm infants fed ad libitum after hospital discharge adjust their volume of intake to account for the energy content of the milk (McGuire 2007). Therefore, fortifying milk may not necessarily result in an overall increase in nutrient intake. Nutrient-fortification of breast milk may be more appropriate for infants who are not fully fed directly from the breast, are unable to consume ad libitum intakes of milk, and have poor growth or nutritional status with on-going additional metabolic requirements.

Finally, considerable uncertainty exists with regard to the effect of growth status during fetal life and early infancy on long term health. Reassuringly, a recent systematic appraisal of observational studies did not find evidence to support a strong association between fetal growth and cardiovascular heath in later life (Huxley 2002). Similarly, although rapid "catch-up" growth has been proposed as a potential contributor to a "metabolic syndrome" that results in long-term adverse cardiovascular outcomes, current evidence suggests that any contribution of diet in early infancy to long-term outcomes of preterm infants is likely to be very small (discussed by Greer 2007).

\section{A U THORS' CONCLUSIONS}

\section{Implications for practice}

There are no data from randomised controlled trials to determine whether providing multicomponent fortification for breastfed preterm infants following hospital discharge affects growth and development.

\section{Implications for research}

Given the potential for nutrient fortification to affect growth and development, this intervention may merit further assessment. Since fortifying breast milk for infants fed directly from the breast is logistically difficult (and has the potential to interfere with breast-feeding), it would be important to determine if mothers would support a trial of this intervention. It may be that a trial should first focus on infants who are not able to consume ad libitum quantities of milk directly from the breast, who have poor growth or nutritional status, or who have on-going additional metabolic requirements, for example due to chronic lung disease. If trials are undertaken, these should aim to determine if exclusive breast-feeding rates affected and to assess measures of maternal satisfaction.

\section{REFERENCES}

\section{References to studies excluded from this review}

Hall 1993 \{published data only\}

Hall RT, Wheeler RE, Rippetoe LE. Calcium and phosphorus supplementation after initial hospital discharge in breast-fed infants of less than 1800 grams birth weight. Journal of Perinatology 1993;13: 272-8.

\section{References to studies awaiting assessment}

O'Connor 2007 \{published data only\}

O'Connor DL, Khan S, Weishuhn K, Vaughan J, Jefferies A, Campbell DM, et al.Growth and nutrient intakes of human milk-fed premature infants provided with extra energy and nutrients after hospital discharge. E-PAS:60:7720.6. Pediatric Academic Societies's Annual Meeting, 2007.

\section{Additional references}

Barker 2002

Barker DJ. Fetal programming of coronary heart disease. Trends in Endocrinology and Metabolism 2002;13:364-8.

\section{Clark 2003}

Clark RH, Thomas P, Peabody J. Extrauterine growth restriction remains a serious problem in prematurely born neonates. Pediatrics 2003;111:986-90.

\section{Cooke 2000}

Cooke RJ, Embleton ND. Feeding issues in preterm infants. Archives of Disease in Childhood 2000;83:F215-8.

\section{Cooke 2003}

Cooke RWI, Foulder-Hughes L. Growth impairment in the very preterm and cognitive and motor performance at 7 years. Archives of 
Disease in Childhood 2003;88:482-7.

\section{Embleton 2001}

Embleton NE, Pang N, Cooke RJ. Postnatal malnutrition and growth retardation: an inevitable consequence of current recommendations in preterm infants?. Pediatrics 2001;107:270-3.

\section{Ewer 1996}

Ewer AK, Yu VY. Gastric emptying in pre-term infants: the effect of breast milk fortifier. Acta Paediatrica 1996;85:1112-5.

\section{Ford 2000}

Ford GW, Doyle LW, Davis NM, Callanan C. Very low birth weight and growth into adolescence. Archives of Pediatrics \& Adolescent Medicine 2000;154:778-84.

Greer 2007

Greer FR. Post-discharge nutrition: what does the evidence support?. Seminars in Perinatology 2007;31:89-95.

\section{Griffin 2002}

Griffin IJ. Post discharge nutrition for high risk neonates. Clinics in Perinatology 2002;29:327-44.

\section{Gross 1980}

Gross SJ, David RJ, Bauman L, Tomarelli RM. Nutritional composition of milk produced by mothers delivering preterm. Journal of Pediatrics 1980;96:641-44.

\section{Hack 1991}

Hack M, Breslau N, Weissman B, Aram D, Klein N, Borawski E. Effect of very low birthweight and subnormal head size on cognitive abilities at school age. The New England Journal of Medicine 1991; 324:231-7.

Huxley 2002

Huxley R, Neil A, Collins R. Unravelling the fetal origins hypothesis: is there really an inverse association between birthweight and subsequent blood pressure?. Lancet 2002;360:659-65.

\section{Kuschel 2004a}

Kuschel CA, Harding JE. Multicomponent fortified human milk for promoting growth in preterm infants. Cochrane Database of Systematic Reviews 2004, Issue 1. [DOI: 10.1002/14651858.CD000343.pub2]

\section{Kuschel 2004b}

Kuschel CA, Harding JE. Protein supplementation of human milk for promoting growth in preterm infants. Cochrane Database of Systematic Reviews 2004, Issue 1. [DOI: 10.1002/14651858.CD000433]

\section{Lucas 1984}

Lucas A, Gore SM, Cole TJ, Bamford MF, Dossetor JF, Barr I, Dicarlo L, Cork S, Lucas PJ. Multicentre trial on feeding low birthweight infants: effects of diet on early growth. Archives of Disease in Childhood 1984;59:722-30

\section{Lucas 1992}

Lucas A, King F, Bishop NB. Postdischarge formula consumption in infants born preterm. Archives of Disease in Childhood 1992;67: $921-2$.

\section{McClure 1996}

McClure RJ, Newell SJ. Effect of fortifying breast milk on gastric emptying. Archives of Disease in Childhood. Fetal and neonatal edition 1996;74:F60-2.

\section{McGuire 2007}

Henderson G, Fahey T, McGuire W. Nutrient-enriched formula versus standard term formula for preterm infants following hospital discharge. Cochrane Database of Systematic Reviews 2007, Issue 4. [DOI: 10.1002/14651858.CD004696.pub3]

\section{Morley 2000}

Morley R, Lucas A. Randomized diet in the neonatal period and growth performance until 7.5-8 y of age in preterm children. American Journal of Clinical Nutrition 2000;71:822-8.

\section{Rigo 2000}

Rigo J, De Curtis M, Pieltain C, Picaud JC, Salle BL, Senterre J. Bone mineral metabolism in the micropremie. Clinics in Perinatology 2000;27:147-70.

\section{Simmer 2000}

Simmer K. Choice of formula and human milk supplement for preterm infants in Australia. Journal of Paediatrics and Child Health 2000;36:593-5.

\section{Tsang 1993}

Tsang RC, Lucas A, Uauy R, Zlotkin S. Nutritional needs of the preterm infant. Scientific basis and practical guidelines. New York: Williams and Wilkins, 1993.

\section{WHO 2001}

The World Health Organization. 54th World Health Assembly. 2001; Vol. 54.2.

* Indicates the major publication for the study 


\section{CHARACTERISTICS OF STUDIES}

Characteristics of excluded studies [ordered by study ID]

Hall 1993 The intervention group received only mineral supplements.

Characteristics of studies awaiting classification [ordered by study ID]

O'Connor 2007

\begin{tabular}{ll}
\hline Methods & Not known \\
\hline Participants & Not known \\
\hline Interventions & Not known \\
\hline Outcomes & Not known \\
\hline Notes & \\
\hline
\end{tabular}


DATA AND ANALYSES

This review has no analyses.

\section{WHAT'S NEW}

Last assessed as up-to-date: 29 May 2007.

22 August 2008 Amended Converted to new review format.

\section{H IS T O R Y}

Protocol first published: Issue 3, 2004

Review first published: Issue 4, 2007

30 May 2007 New citation required and conclusions have changed Substantive amendment

\section{CONTRIBUTIONS OFAUTHORS}

William McGuire and Tom Fahey developed the protocol. Ginny Henderson and William McGuire undertook the electronic and hand searches, screened the title and abstract of all studies identified, and the full text of potentially relevant reports. Each review author independently assessed the methodological quality of the trials, extracted the relevant information and data, and completed the final review.

\section{DECLARATIONS OF INTEREST}

None

\section{SOURCES OF SUPPORT}

\section{Internal sources}

- ANU Medical School, Canberra, Australia.

- Griffith University, Queensland, Australia.

- Royal College of Surgeons in Ireland, Ireland. 


\section{External sources}

- Tenovus Scotland, UK.

\section{NDEX TERMS}

\section{Medical Subject Headings (MeSH)}

*Food, Fortified; *Milk, Human; Infant, Low Birth Weight [ ${ }^{*}$ growth \& development]; Infant, Newborn; Infant, Premature [*growth $\&$ development]

\section{MeSH check words}

Humans 